\title{
A INSERÇÃO DA GINÁSTICA ORIENTAL LIEN CH'I NA EDUCAÇÃo FÍSICA ESCOLAR
}

\author{
Leandro Alves da Cunha ${ }^{1}$, Helena Faria de Barros².
}

${ }^{1}$ Discente do Programa de Mestrado em Educação da Universidade do Oeste Paulista - UNOESTE. Docente de Faculdade de Licenciatura e de Bacharelado em Educação Física. ${ }^{2}$ Docente do Programa de Mestrado em Educação da Universidade do Oeste Paulista - UNOESTE. E-mail: cunha-leandro@ig.com.br

\section{RESUMO}

O presente estudo avaliou a inserção da técnica gímnica oriental Lien Ch i como conteúdo programático da disciplina de Educação Física nas escolas do Ensino Básico, através da visão dos docentes da referida disciplina. As escolas e os professores pertencem à rede pública de ensino do estado de São Paulo, nos municípios de Presidente Prudente-SP e de Araçatuba-SP. A Secretaria de Estado da Educação de São Paulo (S.E.E./SP) realizou tal intervenção capacitando seus docentes nos ano de 2003 e 2004, efetivando a prática do Lien Ch'i nos anos de 2005, 2006 e 2007. Os Parâmetros Curriculares Nacionais (PCN's) atuais sugerem a divisão dos conteúdos de Educação física em três blocos; a) Esportes, jogos, lutas e ginásticas; b) Atividades Rítmicas e expressivas; c) Conhecimentos sobre o corpo. Devido à sua riqueza de opções de trabalho, o Lien Ch 'i pode ser inserido em qualquer dos três blocos supracitados. Somados estes aspectos o nosso interesse foi aguçado para investigar as características desta modalidade, bem como a sua eficácia, motivação e aceitação dos sujeitos envolvidos no processo. Esta pesquisa tem cunho predominantemente qualitativo, cujas características mais significativas são seu conteúdo descritivo e interpretativo. Os dados foram coletados através de uma entrevista transcrita posteriormente e de consultas a documentos. Os docentes estudados $(n=21)$ demonstraram possuir conhecimento sobre a capacitação recebida (Lien Ch'i), no que tange a origem e história, a constituição, composição e os objetivos dos exercícios, bem como, o seu auxílio para maximizar o aprendizado de escolares. Os docentes foram agentes diretos na implantação e desenvolvimento da proposta ocorrida na rede estadual de ensino de São Paulo. Foi observado uma maior reciprocidade, aceitação e participação para com o Lien Ch ii, bem como, melhor aproveitamento das aulas no ciclo I do Ensino Fundamental (de $1^{\text {a }}$ à $4^{\underline{a}}$ séries). Foi detectada uma grande insatisfação sobre as propostas de conteúdos curriculares inseridas na disciplina de Educação Física $(69,3 \%$ ) e uma insatisfação maior ainda, sobre a não continuidade destas propostas inseridas $(85,7 \%)$. Os fatores preponderantes citados para estas insatisfações foram: a imposição das políticas públicas educacionais autoritárias e desrespeitosas aos seus pares; a não continuidade das inserções com a troca de Governo, ou no mesmo Governo, com a troca de Secretario da Educação.

Palavras-chave: Técnica Gímnica Oriental, Lien Ch`i, Ensino Básico, Educação Física Escolar.

\section{THE INTEGRATION OF ORIENTAL LIEN CH `IGYMNASTICS ON PHYSICAL EDUCATION IN SCHOOLS}

\begin{abstract}
The present study evaluated the technique of insertion eastern Lien Ch igymnastic as programmatic content from Physical Education discipline in schools of basic education, through the discipline teachers' view. The schools and the teachers belong to the public teaching service of São Paulo state, in the cities of Presidente Prudente-SP and Araçatuba-SP. The Education Department of São Paulo (SEE / SP) carried out such an intervention enabling its faculty in 2003 and 2004, effecting the practice of Lien Ch'i during the years 2005, 2006 and 2007. The current National Curricular Parameters (PCN's) suggest splitting the content of physical education in three blocks, a) sports, games, wrestling and gymnastics, b) Rhythmic and expressive Activities, c) knowledge about the body. Due to its rich job options, the Lien Ch 'i may be inserted into any of the three blocks mentioned above. Added to these aspects, our interest was keen to investigate the characteristics of this modality and its effectiveness, motivation and acceptance of the people involved in the process. This research is predominantly qualitative, which most significant features are descriptive and interpretive content. Data were collected through an interview transcribed later and documents consultation. The studied teachers $(n=21)$ have demonstrated knowledge about the received training (Lien Ch i) towards to origin and history, constitution, composition and goals of the exercises, as well as its help to maximize schoolchildren learning. The teachers were direct agents in the implementation and development of the proposal which took place in state schools of São Paulo. It was observed greater reciprocity, acceptance and participation for Lien Ch $i$, as well as better use of lessons in the first cycle of primary education (1st to 4th grades). It was detected a strong dissatisfaction over the proposed curriculum content inserted in the discipline of Physical Education $(69.3 \%)$ and an even greater dissatisfaction about the non continuation of these proposals $(85.7 \%)$. The main factors listed for this dissatisfaction were: the imposition of arbitrary and disrespectful public education policies, the non continuation of the "insertions" with government changes or in the same government with a different education secretary.
\end{abstract}

Keywords: Eastern Technical gymnastic Lien Ch `i, Elementary Education, Physical Education. 


\section{INTRODUÇÃO}

Dentre o período de 2003 e 2007 a Secretaria de Estado da Educação de São Paulo (S.E.E./SP) através suas Diretorias Regionais de Ensino do Interior e sua Coordenadoria de Estudos e Normas Pedagógicas (CENP/SEE) inseriu em sua rede de ensino básico uma técnica gímnica oriental denominada Lien Ch $i$ (SÃO PAULO, 2009; JIA, 2004). A implantação começou a ser desenvolvida em novembro de 2003, com os professores de Educação Física na Capital e Grande São Paulo recebendo capacitação, em 2004 teve sua expansão para as diretorias regionais do interior do estado e para outros professores e profissionais da Educação do Estado paulista (SÃO PAULO, 2009). A inserção do Lien Ch'i objetivava proporcionar o que muitas técnicas orientais como o Yoga, a Acumpuntura, o Do-in (massagem) etc, estes técnicas oriundas do oriente aplicadas aqui no ocidente proporcionam a busca do equilíbrio energético corporal, tranqüilidade e calma, e especificamente na escola, bem como, propiciar maior concentração nas aulas, relaxamento muscular, melhorar a postura corporal, diminuir dores no corpo, melhorar o sono, o entusiasmo e a disposição nas atividades escolares e extraescolares, diminuir a agressividade, melhorar o relacionamento com os colegas, melhorar a noção do corpo, consciência corporal e autoestima, propagar e levar os conhecimentos da prática aos familiares, favorecer o desejo de aprender (SÃO PAULO, 2009; JIA, 2004).

Esta inserção governamental e política na rede pública do estado mais rico da União de nosso país motivou-me a desenvolvimento uma pesquisa para o curso de Mestrado em Educação, e o objetivo foi proporcionar aos professores avaliar como se deu a implantação e efetivação resultante do recebimento da capacitação sobre a inserção da técnica gímnica oriental Lien Chì como conteúdo programático na disciplina de Educação Física na rede de Ensino básico (Fundamental e médio) da rede estadual paulista de educação, o estudo concentrou-se nas regiões Oeste e do Estado de São Paulo, especificamente nas cidades de Presidente Prudente-SP e Araçatuba-SP.

No entanto, o presente trabalho teve como objetivo analisar como os professores de Educação Física da Rede Básica de Ensino do estado de São Paulo realizaram a inserção da técnica gímnica oriental Lien Ch ${ }^{\prime}$ nas escolas, bem como, suas respectivas opiniões sobre a referida inserção. A pesquisa concentrou-se nas regiões Oeste e Noroeste do Estado de São Paulo, e os professores entrevistados estavam lotados em cargos nas Diretorias Regionais de Ensino das cidades de Presidente Prudente-SP e Araçatuba-SP.

Como objetivos específicos à pesquisa pretenderam: a) analisar como os professores perceberam o Lien Ch i como conteúdo da Educação Física do Ensino Básico e sua validade; b) verificar o nível de aceitação e da motivação dos professores e dos alunos com relação ao Lien Chi. c) avaliar se com a introdução do Lien Chii houve melhora nos aspectos físicos motores, emocionais, na sociabilizarão, na concentração, na disciplina, entre outros fatores preconizados como objetivos ou justificativas para inserção da técnica gímnica oriental na escola.

\section{METODOLOGIA}

Este estudo pode ser classificado como um estudo "a partir do fato passado", significando que o estudo foi realizado após a ocorrência de variações na variável dependente no curso natural do acontecimento (GIL, 2002). E a inserção da ginástica oriental Lien Ch $i$ na Educação Física Escolar corrobora com este cenário. 
Segundo Marconi e Lakatos (1999), esta pesquisa tem cunho predominantemente qualitativo, cujas características mais significativas são seus conteúdos descritivos e interpretativos.

A pesquisa foi aprovada pela Coordenadoria Central de Pesquisa, protocolo oㅡ 130/09 e pelo Comitê de Ética em Pesquisa, protocolo no 11/2009, ambos os órgãos pertencem à Pró-Reitoria de Pós-graduação e Pesquisa da Universidade do Oeste Paulista UNOESTE. (campus II - Presidente PrudenteSP). Todos os 21 professores entrevistados foram voluntários e os mesmos assinaram, individualmente, um termo de consentimento esclarecido. Os professores eram efetivos ou estáveis pertencentes às Diretorias Regionais de Ensino de Presidente Prudente e Araçatuba, que trabalharam nos anos de 2003 a 2007 e acompanharam, ativamente, a inserção do Lien Ch`ina Educação Física Escolar.

Como procedimentos de análise dos dados coletados foram realizados: uma préanalise que começou por uma leitura flutuante, buscando-se a analogia das respostas, para conhecer as mensagens nelas contidas, margeando-as e deixando-as invadir o pesquisador por impressão, representações, emoções, conhecimentos e expectativas. (BARDIN, 1977; FRANCO, 2003). Este processo foi sequenciado com a criação das categorias de análise, ou seja, operação de classificação dos elementos constitutivos em unidade de análise. As categorias não foram elaboradas e definidas à priori, pois não objetivávamos a obtenção de respostas específicas, portanto, as unidades de análise emergiram da fala, do discurso contido no conteúdo das respostas.

\section{RESULTADOS E DISCUSSÃO}

Partindo do principio que a referida pesquisa teve como objetivo analisar como os professores de Educação Física da Rede Básica de Ensino do Estado de São Paulo realizaram a inserção da técnica gímnica oriental Lien Ch i i nas escolas, bem como, suas respectivas opiniões sobre a referida inserção, podemos inferir que os resultados encontrados satisfazem os propósitos da mesma.

Os professores estudados demonstraram possuir conhecimento sobre a capacitação recebida (Lien Chi), no que tange à origem, à história, a constituição, a composição dos objetivos, os exercícios específicos da técnica, bem como, seu auxílio para maximizar o aprendizado de escolares proporcionando melhora na concentração, na disciplina e tornando o ambiente escolar mais pacífico. Confirmamos que os professores foram agentes diretos na implantação e desenvolvimento da proposta ocorrida na rede estadual de ensino referida.

Os professores apresentaram conhecimento sobre as leis normativas da educação brasileira e encontraram relação entre o conteúdo curricular proposto e as referidas leis. Demonstraram ter utilizado a referida técnica oriental em suas aulas, sendo que a maioria aplicou a técnica oriental Lien Ch $\dddot{i}$, no ensino fundamental. Foram observadas uma maior reciprocidade, aceitação e participação para com - Lien Ch $\dddot{i}$, bem como, melhor aproveitamento das aulas os alunos do ciclo I do Ensino Fundamental (de $1^{\underline{a}}$ à $4^{\underline{a}}$ séries) e nas duas primeiras séries do cilco II do Ensino Fundamental (de $5^{\mathrm{a}}$ à $6^{\mathrm{a}}$ séries), resultados estes, que corroboram com os resultados de pesquisa realizada pela própria S.E.E./SP, publicados em sua página na internet e citado nesta pesquisa.

Foi observado dificuldade na aplicação prática do Lien Ch `i nas duas séries finais do ciclo II do Ensino Fundamental ( $7^{\mathrm{a}}$ e $8^{\mathrm{a}}$ séries $)$ e no Ensino Médio. Segundo os professores entrevistado faltou contextualizar melhor aspecto 
intercultural da inserção proposta para estas séries, fato este, que também corroboram com a citada pesquisa pela S.E.E./SP.

Foram detectados $50 \%$ de insatisfação, quanto à infraestrutura, esta insatisfação foi especificado por dificuldades de encontrar locais sem agitação em algumas escolas para prática do Lien Ch i, falta de material didático para o professor estudar e entender melhor a proposta atividade. Quanto à falta de material prático como foram citados; os CDs com as músicas específicas, falta de rádio para a aplicação prática do Lien C'hi.

Quanto à proposta de inserção do Lien C'hi como conteúdo programático da disciplina de Educação Física na SEE/SP a insatisfação dos professores foi de 69,3\%, o fator preponderante citados foi à imposição autoritária e desrespeitosa aos seus pares nestas inserções, pois por decisão única da SEE/SP e alguns poucos professores coordenadores resolveram pela inserção não consultando a todos os pares (professores, alunos, pais de diferentes regiões) efetivamente. No entanto, os professores receberam capacitação e efetivam sua aplicação.

Outra insatisfação dos professores e maior ainda $(85,7 \%)$ foi sobre a não continuidade destas propostas inseridas (Lien C`hi) após 2008. A não continuidade das propostas inseridas na Educação com a troca de Governo, ou no mesmo Governo, com a troca de Secretario da Educação geralmente são interrompidas desperdiçando muito dinheiro e insatisfação aos funcionários públicos, além de explicitar desrespeito à comunidade, prejuízo aos cofres públicos, entre outros fatores negativos. O Lien Ch $\mathrm{i}$ foi mais um destes casos, pois, como citado por um professor entrevistado, esta técnica poderia ser enquadrada na Nova Proposta Curricular implantada após a capacitação do Lien Chii, a partir de 2008, pela S.E.E./SP".

\section{CONSIDERAÇÕES FINAIS}

Esta nova proposta curricular objetiva abrir o leque de conteúdos da disciplina de Educação Física (SÃO PAULO, 2008), porém não traz a ginástica oriental com integrante dos conteúdos apresentados nos materiais didáticos mostrando a não continuidade do Lien C'hi. Sendo assim, o Governo paulista após gastar muito dinheiro para capacitar os professores não utiliza a atividade com integrante em uma nova proposta pedagógica e que o próprio Governo afirma ser uma reformulação da proposta vem decorrendo a anos no estado.

A experiência com esta pesquisa corrobora com outras mostrando inserções de conteúdos ou reformas curriculares sendo impostas, autoritariamente, não se enraízam e caem no esquecimento. Restando-nos ver os recursos e esforços serem desperdiçados por reformas $e$ inserções de conteúdos sendo frequentemente imposta de cima para baixo, uma atropelando a outra, desconsiderando a importância de seus pares, os professores e os alunos, envolvidos na educação como parceiros efetivos na definição dos novos rumos curriculares.

Os professores participantes relataram pontos positivos, negativos e opinaram com

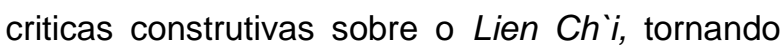
assim, esta pesquisa de considerável importância deixando os seus registros para serem consultados quando futuras propostas de componentes curriculares acontecerem.

Podemos também relacionar os achados desta pesquisa com os dizeres de Nereide Saviani (2008), quando a mesma diz que as políticas públicas em nosso país sofrem de uma espécie de "Vício Autoritário", onde fica explicito que os políticos da vez fazem o que bem entendem quando está no poder, deixando a educação pública refém de suas concepções e interesses. Para nós um dos antídotos para esta 
questão seria programarmos uma lei fiscal para a Educação, onde uma proposta construída respeitando todos os pares envolvidos seria desenvolvida e os governos sucessores teriam o dever de dar continuidade e realizar reparos necessários que surgem no decurso da efetivação de uma proposta curricular.

\section{REFERENCIAS}

BARDIN, L. Análise de conteúdo. Lisboa: Persona, 1977.

FRANCO, M. L. P. B. Análise de conteúdo. Brasília: Plano, 2003.

GIL, A. C. Como elaborar projeto de pesquisa: como classificar as pesquisas? São Paulo. 4.ed. São Paulo: Atlas, Cap. 4, 2002.

JIA, J. E. Ch'an Tao, Conceitos Básicos: Medicina Tradicional Chinesa Lien $\mathrm{Ch}^{\prime} \mathbf{i}$ e Meditação. São Paulo: Ícone, 2004.

MARCONI, M. D. A.;LAKATOS, E. M. Técnicas de pesquisa. 4. ed. São Paulo: Atlas, 1999.

SÃO PAULO. Secretaria de Estado da Educação de São Paulo. Proposta Curricular do Estado de São Paulo - Educação Física. Coordenadoria de Estudos e Normas Pedagógicas (CENP/SEE). Imprensa Oficial, 2008. Disponível em: <http://cenp.edunet.sp.gov.br/index.htm>. Acesso em: 25 abr. 2009.

SAVIANI, N. Currículo e trabalho pedagógico: prescrições políticas, prática negociada. In: CONGRESSO DO SINPRO MINAS, 10, 2008. Anais eletrônico... Disponível em: <http://www.sinprominas.org.br/imagensDin/arqui vos/361.doc>. Acesso em: 25 abr. 2009. 